\title{
PORT SITE INFECTIONS FOLLOWING LAPAROSCOPIC CHOLECYSTECTOMY
}

\author{
SADIA SAJMIN SIDDIQUA ${ }^{1}$, MD. AZIZUL ISLAM KHAN ${ }^{2}$, MD. ARIF UDDIN KHAN ${ }^{3}$, SHOVON SAYEED ${ }^{3}$
}

\begin{abstract}
Background: Port site infections (PSIs) following laparoscopic cholecystectomy is an infrequent complication. Among the causes of PSIs Mycobacterium tuberculosis is rare but it has been increasingly recognized in the recent years. Lack of awareness of this complication leads to prolonged morbidity. Early diagnosis and treatment is important for theresolution of the disease.
\end{abstract}

Methods: This was an observational descriptive study carried out on patients who underwent laparoscopic cholecystectomy. In patients of PSIs, Gram and AFB staining with culture \& sensitivity of pus and biopsy of abscess wall or sinus tract were obtained as per need to reach the diagnosis. Patients were treated accordingly.

Results: The rate of PSIs was 3.92\% in this study. Age, sex \& body weight have no impact on PSIs. Diabetes mellitus, hypertension, hypothyroidism, acute cholecystitis \& spillage of bile or stone during the procedure increases the rate of PSIs. Epigastric port was affected more than that of other ports. Among the causes of port site infections in $55.18 \%$ cases it was with Gram +ve bacteria, in $34.49 \%$ cases with Gram -ve bacteria, in $1.72 \%$ cases atypical mycobacteria, in $5.17 \%$ cases Mycobacterium tuberculosis $\&$ in $3.44 \%$ cases no organisms were found. Most of the PSIs developed early within one month \& responded well with antibiotics. Diagnosisof port site tuberculosis was established by histopathological examination of tissue from abscess wall or sinus tract $\&$ treated as per WHO guide line. No recurrence noted at 2 years follow up.

Conclusion: Port site tuberculosis after laparoscopic cholecystectomy is a rare entity. The present study is an attempt to make surgeons aware of this rare complication. Early diagnosis and proper treatment are prerequisites to the successful outcome. Strict adherence to well established sterilization protocol is a must for the prevention.

Key words: Laparoscopic surgery; Port site infection; Tuberculosis; Sterilization.

Received: 07 August 2017

Accepted: 10 June 2018

DOI: http:// dx.doi.org/ 10.3329/ bjmed.v29i2.37938

\section{Introduction}

Any surgical wound is a potential site of infection. The goal of modern wound care is prevention of infection and timely restoration of the body to its previous state of normal form and function. It is this very goal that has led to the development of laparoscopic surgery. The modern era of laparoscopy started in 1987 when Phillipe Mouret performed the first laparoscopic cholecystectomy. ${ }^{1}$ With advances in the field of laparoscopic surgery a wide range of surgeries are being performed laparoscopically. As the number of surgeries increased newer subset of complications surfaced. ${ }^{2}$

Surgical site infections(SSIs) are the most common healthcare associated infections (HAIs), accounting for $31 \%$ of all HAIs among hospitalized patients . $^{3}$ SSIs rate is much higher in conventional surgical procedures than in laparoscopic surgery. ${ }^{4,5,6}$ But port site infective complications are not uncommon ${ }^{7}$ Port site infections are of two broad varieties based on

1. Senior Consultant of Surgery, Sarkari Karmachari Hospital, Dhaka-1000

2. Assistant Professor (Cardiac Surgery), NICVD, Dhaka

3. Junior Consultant of Surgery, Sarkari Karmachari Hospital, Dhaka-1000

Correspondence: Dr. Sadia Sajmin Siddiqua, Senior Consultant of Surgery, Sarkari Karmachari Hospital, Dhaka-1000, Cell Phone: 01711693688,Email: sadia-_siddiqua@hotmail.com

Bangladesh J Medicine 2018; 29 : 51-58 
the timing of presentation. The more common type manifests early within a week or so following the surgical procedure with pain or tenderness, wound discharge and erythema around the port site. They are usually caused by Gram positive or Gram-negative bacteria and respond well to the common antimicrobial agents. Other variety- the delayed types was chronic in nature, commonly caused by mycobacteria and manifests nearly a month or so after the surgery in the form of nodules, abscess or persistent discharging sinus at the port sites. These wounds usually not respond to common antibiotics. Among the mycobacterial isolates atypical mycobacteria, also called nontuberculous mycobacteria (NTM), which are ubiquitous in nature and have a predilection to involve skin and subcutaneous tissues, are mainly responsible for such chronic infection.$^{8}$ But port site tuberculosis(TB) following laparoscopic cholecystectomy is rare with only a few isolated cases reported in the literatures. ${ }^{9-16}$ Tubercular port site infection is a concern for the laparoscopic surgeon as it leads to prolong suffering of the patient. It washes away all the advantages of laparoscopic surgery and irritate the surgeon as well as the patient. Complications can occur even in best hands. The only surgeon who does not face complication is one who does not operate. Early recognition of complications and immediate treatment is important.

\section{Patients and methods}

This observational descriptive study was done during the period of January 2008 to December 2016. During this time, we performed 1478 laparoscopic cholecystectomies at Sarkari Karmachari Hospital, Dhaka and General \& Child Hospital, Narshingdi. Currently prevalent aseptic practice of immersing laparoscopic instruments for 20 minutes in $2 \%$ alkaline gluteraldehyde solution were ensured in all cases. All patients were given 3 doses of injection ceftriaxone $1 \mathrm{gm}$ intravenously 12 hourly, $1^{\text {st }}$ dose during induction of anesthesia. Inaddition, inj.metronidazole 500mg 8 hourly for 24 hours. In patients with acute cholecystitis or empyema gall bladder antibiotics were continued for a longer period depending on the clinical situation. All operations were done by using standard 4 ports procedure with reusable instruments. Sub hepatic drain tube was used in case of acute cholecystitis or empyema gall bladder or spillage of bile from gall bladder during its separation from liver bed. Gall bladder was extracted through epigastric or umbilical port as per convenience. In case of acute cholecystitis or empyema gall bladder powder free gloves bag was used to extract the gall bladder through the umbilical port.
Drain tube was removed after 48 hours in all patients. Linea alba at umbilical port was closed with no $1 / 0$ vicryl. All the skin incisions were closed with no 4/0 prolene. Stiches were removed after 8 th postoperative day. Out of 1478 patients 58 patients presented to us with port site infection. Among these 58 patients 51 presented within one month $\& 7$ presented after one month or later from the day of operation with port site infection. We also studied 3 other patients who presented to us with recurrent discharging sinus at epigastric port following laparoscopic cholecystectomy done by 3 fellow surgeons (one each).

Patients of this study were evaluated by detailed history and thorough physical examination \& relevant investigations. Their discharge certificates following laparoscopic cholecystectomy were taken into consideration for their operative details. Complete hematological and biochemical examination, $\mathrm{x}$-ray chest and ultrasonogram of the abdomen were done in all the patients. Patients presenting with abscess were subjected to drain the abscess and regular dressing of the wound with $10 \%$ povidon iodine solution. Pus from patient with abscess (after drain) and those with discharging sinus were sent for Gram and acid-fast bacillus(AFB) staining and culture sensitivity in both aerobic and anaerobic environment. Broad spectrum antibiotic started \& changed if needed as per antibiogram. Tissue was collected by curettage from sinus tract and abscess wall of patients presented after one month or those presented within one month but not responded or recurred after treatment and sent for histopathological examination. Serology (IgG and IgM) for tuberculosis (ELISA) and tuberculin test were done as supportive evidence when suspicious of mycobacterial infection. Culture \& sensitivity for Mycobacterium tuberculosis and other advanced diagnostic tests like polymerase chain reaction $\&$ transcription mediated amplification not needed in these study patients for their management. Patients with tubercular port site infection were treated with antitubercular (anti-TB) drugs as per WHO guide line and followed up for 2 years after the completion of treatment.

\section{Results}

Out of 1478 laparoscopic cholecystectomy 58(3.92\%) patients developed port site infections(PSIs). Among 58 patients of PSIs 51 presented early within one month \& 7 presented after one month or more following the day of operation. Age of the patients of this study ranges from 20-72 years. Most of the patients were female. Weight of the patients ranged from 45 to $81 \mathrm{Kg}$. Port site infections were significantly more in patients with diabetes mellitus (DM), 
hypertension (HTN), hypothyroidism, acute cholecystitis \& spillage of bile or stone during separation of gall bladder from liver bed. PSIs were significantly more in epigastric port than umbilical or lateral ports (Figure 1,2).

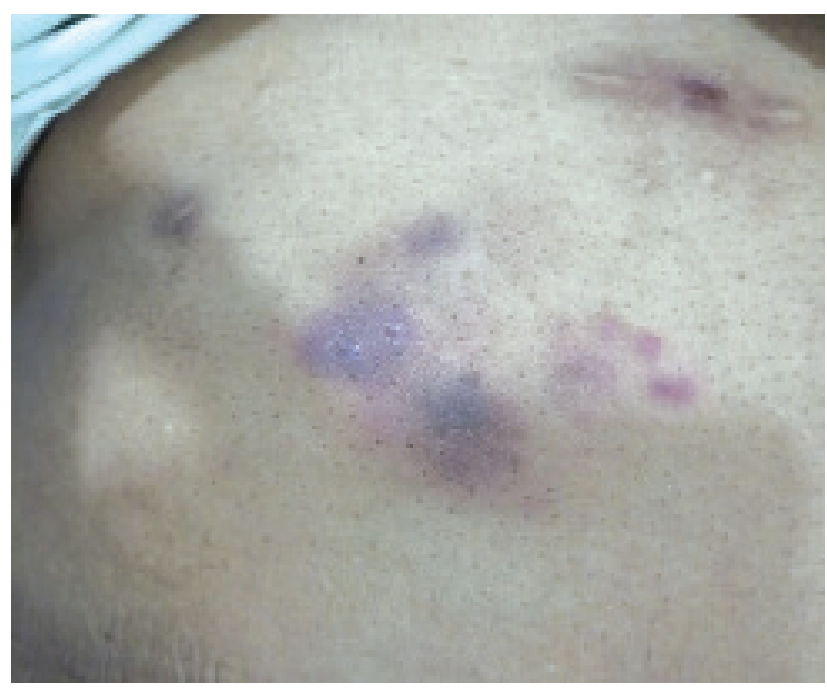

Fig.-1: Typical bluish colored nodules near laparoscopic ports

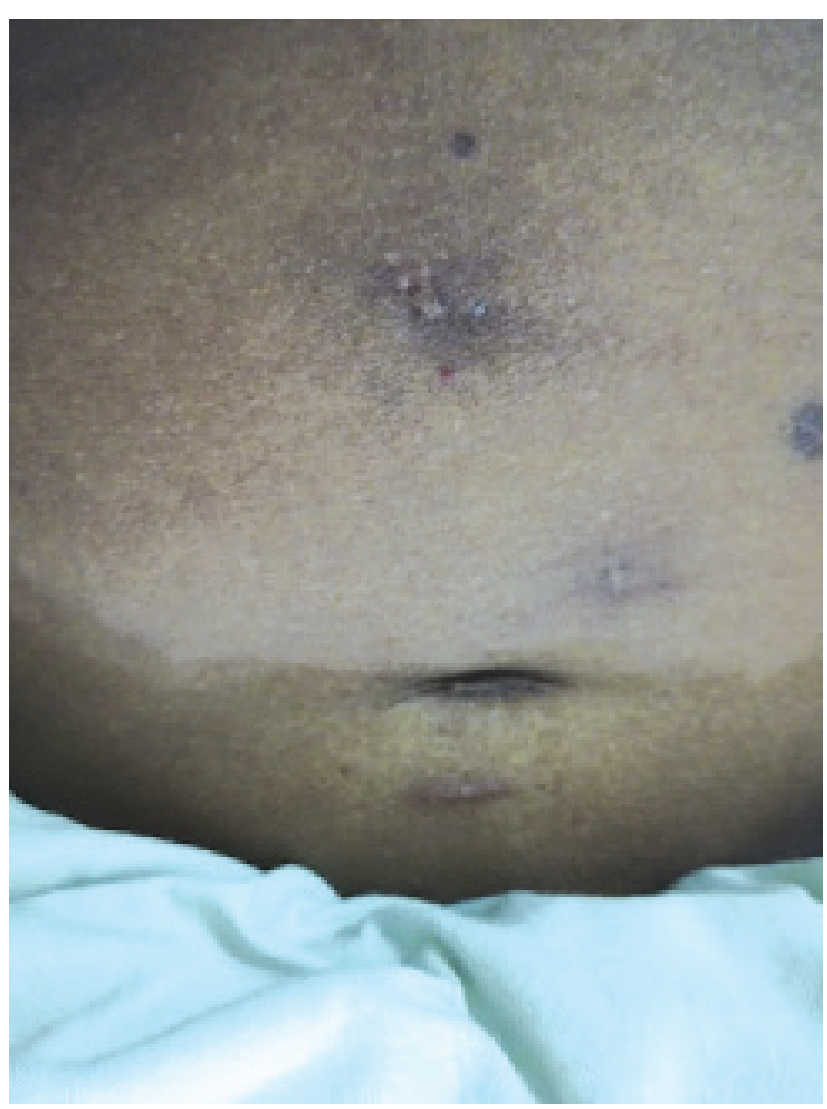

Fig.-2: Tubercular nodules nearby laparoscopic ports.
Table- I. Demographic and clinical profile of the patients operated by us.

Table- I

Demographic and clinical profile of the patients operated by us.

\begin{tabular}{|c|c|c|c|}
\hline Variables & $\begin{array}{l}\text { Without PSI } \\
\qquad(\mathrm{n}=1420)\end{array}$ & $\begin{array}{l}\text { I With PSI } \\
\qquad(\mathrm{n}=58)\end{array}$ & $\begin{array}{c}\mathrm{P} \\
\text { value }\end{array}$ \\
\hline Age (Mean \pm SD) & $\begin{array}{c}46.0 \pm 16.8 \\
(20-72)\end{array}$ & $\begin{array}{c}44.9 \pm 13.9 \\
(23-65)\end{array}$ & 0.623 \\
\hline Sex & & & 0.558 \\
\hline Male (\%) & $78(5.5 \%)$ & $4(6.9 \%)$ & \\
\hline Female (\%) & $1342(94.5 \%)$ & $54(93.1 \%)$ & \\
\hline $\begin{array}{l}\text { Weight in } \mathrm{KG} \\
(\text { Mean } \pm \mathrm{SD})\end{array}$ & $\begin{array}{l}52.40 \pm 15.8 \\
(45-75 \mathrm{~kg} .)\end{array}$ & $\begin{array}{c}54.20 \pm 14.8 \\
(48-81 \mathrm{~kg})\end{array}$ & 0.394 \\
\hline Co-morbidities & & & \\
\hline DM (\%) & $63(4.44 \%)$ & $8(13.79 \%)$ & $0.001^{*}$ \\
\hline HTN (\%) & $48(3.38 \%)$ & $6(10.34 \%)$ & $0.006^{*}$ \\
\hline Hypothyroidism (\%) & $0(0.0 \%)$ & $3(5.5 \% 5.17)$ & $<0.001^{*}$ \\
\hline $\begin{array}{l}\text { Clinical diagnosis } \\
\text { of Gall bladder }\end{array}$ & & & $<0.001^{*}$ \\
\hline $\begin{array}{l}\text { Chronic cholecystitis } \\
(\%)\end{array}$ & $\begin{array}{c}1354 \\
(95.4 \%)\end{array}$ & $\begin{array}{c}46 \\
(79.3 \%)\end{array}$ & \\
\hline $\begin{array}{l}\text { Acute cholecystitis } \\
(\%)\end{array}$ & $\begin{array}{c}66 \\
(4.6 \%)\end{array}$ & $\begin{array}{c}12 \\
(20.7 \%)\end{array}$ & \\
\hline
\end{tabular}

Data were expressed as mean \pm SD and frequency (\%) Unpaired student t-test for quantitative variables and Chi-square test for qualitative variables, *significant

Table-II. Association of port site infection with port of extraction of gall bladder in patients operated by us.

\section{Table-II}

Association of port site infection with port of extraction of gall bladder in patients operated by us.

\begin{tabular}{lccc}
\hline $\begin{array}{l}\text { Port of extraction } \\
\text { of gall bladder }\end{array}$ & $\begin{array}{c}\text { Without PSI } \\
(\mathrm{N}=1420)\end{array}$ & $\begin{array}{c}\text { With PSI } \\
(\mathrm{n}=58)\end{array}$ & $\begin{array}{c}\mathrm{P} \\
\text { value }\end{array}$ \\
\hline Epigastric (\%) & $1194(84.1 \%)$ & $34(58.6 \%)$ & $<0.001^{*}$ \\
Umbilical (\%) & $226(15.9 \%)$ & $24(41.4 \%)$ & \\
\hline
\end{tabular}

Chi-square test, ${ }^{*}$ significant

Table-III.Association of port site infection with spillage of bile or stone during separation of gall bladder from liver bed in patients operated by us. 
Table-III

Association of port site infection with spillage of bile or stone during separation of gall bladder from liver bed in patients operated by us.

\begin{tabular}{lccc}
\hline $\begin{array}{l}\text { Spillage of bile } \\
\text { /stone }\end{array}$ & $\begin{array}{c}\text { Without PSI } \\
(\mathrm{n}=1420)\end{array}$ & $\begin{array}{c}\text { With PSI } \\
(\mathrm{n}=58)\end{array}$ & $\begin{array}{c}\mathrm{P} \\
\text { value }\end{array}$ \\
\hline Spillage of bile/ & 10 & 14 & $<0.001^{*}$ \\
stone (\%) & $(00.70 \%)$ & $(24.14 \%)$ & \\
No spillage & 1410 & 44 & \\
& $(99.29 \%)$ & $(75.86 \%)$ & \\
\hline
\end{tabular}

Chi-square test, *significant.

Table-IV. Incidence of port site infection in different ports in patients operated by us.

Table-IV

Incidence of port site infection in different ports in patients operated by us.

\begin{tabular}{lccc}
\hline $\begin{array}{l}\text { Port involved with } \\
\text { infection }\end{array}$ & Frequency & Percentage & $\begin{array}{c}\mathrm{P} \\
\text { value }\end{array}$ \\
\hline Epigastric & 36 & 62.1 & $<0.001^{*}$ \\
Umbilical & 10 & 17.2 & \\
Lateral & 4 & 6.9 & \\
More than one port & 8 & 13.8 & \\
\hline Total & 58 & 100.0 & \\
\hline
\end{tabular}

One sample Chi-square test, *significant
Regarding the cause of infection in most of the cases $(89.67 \%)$ it was with non-specific microorganisms, $5.17 \%(3)$ byMycobacterium tuberculosis, $1.72 \%(1)$ by atypical mycobacteria and in $3.44 \%(2)$ cases no microorganism was isolated. Overall infection rate by Mycobacterium tuberculosis was only $0.20 \%$.

Table $-\mathrm{V}$. Type of microorganism causing port site infection following laparoscopic cholecystectomy in patients operated by us.

Table $-\mathbf{V}$

Type of microorganism causing port site infection following laparoscopic cholecystectomy in patients operated by us.

\begin{tabular}{lcc}
\hline Microorganism & $\begin{array}{c}\text { No of } \\
\text { patient }\end{array}$ & $\begin{array}{c}\text { Percentage } \\
(\%)\end{array}$ \\
\hline Staphylococcus aureus & 28 & 48.27 \\
Enterobacterspp. & 11 & 18.96 \\
E.coli & 9 & 15.51 \\
Enterococcus spp. & 04 & 06.89 \\
No growth & 02 & 03.44 \\
Mycobacterium tuberculosis & 03 & 05.17 \\
Atypical Mycobacteria & 01 & 01.72 \\
\hline
\end{tabular}

Table-VI. Demographic and clinical profile of the patients with tubercular port site infection.

Table VI

Demographic and clinical profile of the patients with port site tuberculosis.

\begin{tabular}{|c|c|c|c|c|c|c|c|c|}
\hline $\begin{array}{l}\text { S1. } \\
\text { no }\end{array}$ & $\begin{array}{l}\text { Age } \\
\text { in yrs }\end{array}$ & Sex & $\begin{array}{l}\text { Body } \\
\text { wt. in } \\
\mathrm{KG}\end{array}$ & $\begin{array}{l}\text { Comorbidity } \\
\text { DM/HTN/History of or } \\
\text { contact with TB }\end{array}$ & $\begin{array}{l}\text { GB } \\
\text { retrieval } \\
\text { port }\end{array}$ & $\begin{array}{l}\text { HPE of excised } \\
\text { GB }\end{array}$ & $\begin{array}{l}\text { Time of } \\
\text { presentation } \\
\text { from initial } \\
\text { surgery }\end{array}$ & $\begin{array}{l}\text { Mode of } \\
\text { presentation to } \\
\text { us }\end{array}$ \\
\hline 1 & 39 & Female & 57 & none & epigastric & $\begin{array}{l}\text { Chronic calculus } \\
\text { cholecystitis }\end{array}$ & 43 days & $\begin{array}{l}\text { Epigastric port } \\
\text { site abscess }\end{array}$ \\
\hline 2 & 53 & Female & 59 & none & epigastric & do & 37 days & Do \\
\hline 3 & 34 & Female & 61 & $\begin{array}{l}\text { Husband on TB } \\
\text { treatment for } 4 \text { months }\end{array}$ & epigastric & do & 56 days & Do \\
\hline 4 & 35 & Female & 58 & none & epigastric & do & 45 days & $\begin{array}{l}\text { Discharging } \\
\text { sinus at } \\
\text { epigastric port }\end{array}$ \\
\hline 5 & 64 & Female & 56 & none & epigastric & do & 38 days & Do \\
\hline 6 & 47 & Female & 55 & none & epigastric & do & 48 days & Do \\
\hline
\end{tabular}

Patients of S1. No. 1-3 operated by us \& S1. No. 4-6 operated by 3 other fellow surgeons. 
Table VII

Investigation findings of the patients with port site tuberculosis at initial presentation to us.

\begin{tabular}{|l|l|l|l|l|l|l|l|l|l|l|l|}
\hline $\begin{array}{l}\text { Sl. } \\
\text { no }\end{array}$ & $\begin{array}{l}\text { HCT } \\
\%\end{array}$ & $\begin{array}{l}\text { ESR } \\
\mathrm{mm} / \mathrm{hr}\end{array}$ & $\begin{array}{l}\text { CRP } \\
\mathrm{mg} / \mathrm{L}\end{array}$ & $\begin{array}{l}\text { TC } \\
/ \mathrm{mm}^{3}\end{array}$ & $\begin{array}{l}\text { Neutrophil } \\
\%\end{array}$ & CXR & $\begin{array}{l}\text { Serology } \\
\text { IgG\& IgA) } \\
\text { for TB }\end{array}$ & MT & $\begin{array}{l}\text { Gm/AFB } \\
\text { staining }\end{array}$ & $\begin{array}{l}\text { Routine } \\
\text { culture } \\
\text { pus }\end{array}$ & HPE \\
\hline 1 & 38 & 55 & 12 & 5000 & 58 & NAD & Positive & positive & negative & No growth & $\begin{array}{l}\text { Granulomatous } \\
\text { inflammation } \\
\text { consistent with } \\
\text { tuberculosis }\end{array}$ \\
\hline 2 & 42 & 63 & 18 & 10000 & 71 & NAD & positive & positive & negative & No growth & do \\
\hline 3 & 36 & 70 & 19 & 6500 & 53 & NAD & positive & positive & negative & No growth & do \\
\hline 4 & 43 & 78 & 15 & 8000 & 64 & NAD & positive & positive & negative & No growth & do \\
\hline 5 & 41 & 73 & 17 & 4100 & 59 & NAD & positive & positive & negative & No growth & do \\
\hline 6 & 39 & 87 & 21 & 9300 & 68 & NAD & positive & positive & negative & No growth & do \\
\hline
\end{tabular}

Patients of Sl. No. 1-3 operated by us \& Sl. No. 4-6 operated by 3 other fellow surgeons.

Table-VII. Investigation findings of the patients with port site tuberculosis at initial presentation to us.

Out of 51 patients presented early within one month48 patients responded well with antibiotics \& local wound care without recurrence of infection. In 3 patients infection recurred with Staphylococcus aureus in the following month. Of these 3 patients 1 had scabies $\&$ in other 2 diabetes became uncontrolled. These 3 patients were treated accordingly with treatment of diabetes and scabies along with antibiotics as per antibiogram.

Patients diagnosed as port site tuberculosis treatment started with Cat-I anti-TB drugs. While on anti-TB drugs for 3 months, the patient whose husband also had TB-complained of back pain and diagnosed as spine TB and treatment continued for 12 months. Another patient presented with multiple small abscesses over anterior abdominal wall between epigastric port and umbilicus 4 months after completion of Cat-I treatment. Histopathological examination of abscess wall revealed granulomatous inflammation consistent with tuberculosis and diagnosed as tubercular abscess. Treatment started with Cat-II anti- TB drugs. Remaining 4 patient treated for 6 months as per Cat-I. None of the 6 patients developed any recurrence of the disease up to 2 years following completion of the schedule. PSI by atypical mycobacteria was treated with combination of oral Ciprofloxacin \& Clarithromycin for 12 weeks.

\section{Discussion}

Laparoscopic surgery comes with its own subset of complications starting from the creation of pneumoperitoneum and the effects there of. The incidence of port site infection following laparoscopic surgery are less than that of open procedure because laparoscopic surgery is minimally invasive and have less impact on immune system. ${ }^{17}$ Incidence of port site infection in our study was $3.92 \%$ which was less than some studies ${ }^{18-22} \&$ more than some other studies. ${ }^{7,23-25}$.Population, sterilization technique \& environmental factors may be responsible for the difference among these studies. ${ }^{26}$ Age, sex $\&$ body weight have no impact on the rate PSIs as it was shown in other study. ${ }^{27,28}$ Diabetes, hypertension, hypothyroidism, acute cholecystitis and spillage of bile during the procedure increase the rate of PSIs significantly as it was shown in other studies. ${ }^{22,25,29,30}$ In our study epigastric port was involved significantly in higher number of cases than other ports as it was shown in some study. $7,8,26,31$ This may due to maximum use of the epigastric port during the procedure. In another study it was shown umbilical port wasinvolved in higher number of cases; this might be related to umbilical flora and gall bladder extraction through umbilical port in single port surgery $^{32}$. In our study most of the PSIs developed early -within one month following laparoscopic cholecystectomy as it was seen some studies. $7,8,33$ Among the causative organisms of PSIs in majority of cases it was due to Gram positivebacteria (55.17\%). In $34.48 \%$ cases of PSIs it was by Gram negativebacteria. These findings are consistent with some other studies ${ }^{8,34}$. In our study among causes of PSIs it was $5.17 \%$ cases byMycobacterium tuberculosis. As a whole the rate of PSIs by Mycobacterium tuberculosis was $0.20 \%$. This rate of PSIs 
with Mycobacterial tuberculosis consisted with another study. ${ }^{26}$ The complication- port site tuberculosis is neither directly related to the laparoscopy nor to the surgical techniques and hence emerges as an enigmatic embarrassment for the patient as well as the surgeon.$^{2}$ It assumes paramount importance to tackle these complications in developing countries like Bangladesh who struggle to cover the costs associated with management and control programs of TB.

Port site tubercular infection is commonly exogenous (primary), but it can be endogenous (secondary) also. Exogenous mode of transmission include improper sterilization of instruments and use of boiled tape water for rinsing laparoscopic instruments after immersion in $2 \%$ gluteraldehyde solution from actively infected operation theatre(OT) staffs or surgical team or from patients attendants in the early postoperative period when wounds kept open before complete healing.$^{35-37}$ Characteristic pathological lesion found in tuberculosis is called tubercle or tuberculoma- is one type of granulomatous inflammation. Atypical mycobacteria can also produce granulomatous inflammation but not tubercle or tuberculosis. ${ }^{35,38}$

The gold standard for the diagnosis of tuberculosis is demonstration of AFB under the microscope, but only $50 \%$ of the cases are smear positive. ${ }^{39}$ Extra pulmonary TB is less common than pulmonary TB. As a consequence, the diagnosis of extra pulmonary TB can be more challenging. So, culture and histopathological examination is more important.$^{40}$ As the organism is slow grower,emphasis given on histopathological examination of infected tissue at involved site. In case of doubt advanced diagnostic tests (available only in a limited no of hospitals) nucleic acid amplification (NAA) tests like polymerase chain reaction(PCR) or transcription mediated amplification done.${ }^{40}$ Positive tuberculin test indicates the person had subclinical infection or is suffering from clinical tuberculosis. ${ }^{35}$ Serology(IgG and IgA) for TB may also be positive in atypical mycobacterial infection.${ }^{13}$ Drug sensitivity is important in those with a previous history of TB, treatment failure and those who are resident in or have visited an area of high prevalence of resistance or who are HIV-positive .40

In our study none of the patients of tubercular PSIs had any predisposing factors like diabetes mellitus, steroid therapy, malnutrition, long pre or postoperative hospital stay or intra-abdominal tubercular foci as revealed at laparoscopy which is consistent with some other studies. ${ }^{2,11,37,38}$ In all the cases epigastric port was involved which is the mostly used port for the procedure. Diagnosis established by histopathological examination in all the cases as in other series. 2, 9, 11,41 Port site tuberculosis of the patient of this study with spine TB may be secondary tuberculosis. The patient presented with multiple small abscess over anterior abdominal wall after completion of category-I anti-TB drugs were treated as relapse, may be a true relapse or a reinfection either from endogenous or exogenous source; multi drug resistant tuberculosis(MDR-TB) unlikely as in such case it would not response to cat-II anti-TB drugs.

Delayed presentation of port site infection, absence of systemic features of TB at time of primary operation, completion of 4 months of TB treatment by the husband of one patient and absence of contact history in others of the study group strongly suggest the likely source of infection was in the operation theatre. In operation theatre aseptic precautions taken by operation theatre(OT) staffs and none of them were suffering from TB. Considering all these most likely transmissions would be via the laparoscopic instruments as it shown in other studies. $2,8,9,42,43$

It is widely agreed that $2 \%$ gluteraldehyde achieves high level of disinfection and not sterilization. Several publications have highlighted failure to sterilize the instruments if soaked for 20 minutes in $2 \%$ alkaline gluteraldehyde solution. When $2 \%$ alkaline gluteraldehyde is used, careful precleaning of dismantled instruments before their immersion in the disinfectant, use of the agent at the room temperature $\left(25^{\circ} \mathrm{C}\right)$ and frequent checks of the gluteraldehyde concentration is recommended. The advanced sterilization systems such as STERRAD, which uses gas plasma technology to kill bacteria at low temperature or ethylene oxide gas may be used to sterilize laparoscopic instruments.$^{2,8,11,13,16,42,43}$

\section{Conclusion}

The present study is an attempt to make surgeons aware about port site infection specially tuberculosis following laparoscopic cholecystectomy. It is imperative that $2 \%$ alkaline gluteraldehyde solution which is used for sterilization should be regularly changed and minimum immersion time should be more than 20 minutes after proper washing and cleaning of dismantled instruments under running water. Ethylene oxide gas plant sterilization may be more effective method of sterilization. Strict adherence to the well-established sterile protocols is a must to avoid complications. High index of suspicion, early diagnosis and treatment with 
optimum counsellingof patient is important for the recovery.

\section{References}

1. Mouret P. How I developed laparoscopic cholecystectomy. Ann Acad Med Singapore, 1996; 25:744-47.

2. Sandeep B, Neeraj K, Tariq PA. Port site tuberculosis after laparoscopic cholecystectomy: A study of 20 cases. Annals of International Medical and Dental Research, 2017; 3(4):20-24.

3. Magill SS, Hellinger W, Cohen J, KAY R, Bailey C, Boland B, et al. Prevalence of healthcare-associated infections in acute care hospitals in Jacksonville, Florida. Infect Control Hosp Epidemiol, 2012;33:28391.

4. Lilani SP, Jangale N, Chowdhury A, Daver GB. Surgical site infection in clean and cleancontaminated cases. Indian $J$ Med Microbial, 2005;23:249-52.

5. Brill A, Ghosh K, Gunnarsson C, Rizzo J, Fullum T, Maxey C, Brossette S. The effects of laparoscopic cholecystectomy, hysterectomy and appendectomy on nosocomial infection risks. Surg.Endosc, 2008;22:1112-18.

6. Richards C, Edwards J, Culver D, Emori TG, Tolson J, Gaynes R. Does using a laparoscopic approach to cholecystectomy decrease the risk of surgical site infection? Ann Surg,2003; 237:358-62.

7. Kartik S, Augustine AJ, Shibumon MM, Pai MV. Analysis of laparoscopic port site complications: A descriptive study. J Minim Access Surg, 2013;9:5964.

8. Prakash KS, Tushar SM, Satyajit R, Susanta M, DiptiM.Port site infection in laparoscopic surgery: A review of its management. World $J$ Clin Cases, 2015;3(10):864-71.

9. Ramesh H, Prakash K, Lekha V, Jacob G, Venugopal A, Venugopal B. Port - site tuberculosis after laparoscopy: Report of eight cases. Surg Endosc, 2003; 17:930-32.

10. Mansoor T, Rizvi SA, Khan RA. Persistent port-site sinus in a patient after laparoscopic cholecystectomy: Watch out for gallbladder tuberculosis. Hepatobiliary Pancreat Dis Int, 2011;10:328-29.

11. GuptaP, Guleria S, Mathur SR, Ghosh R. Port site tuberculosis: A case report and review of literature. Indian J Tuberc, 2012;59:32-35.

12. Cunnigaiper ND, Venkatraman S. Port site tuberculosis: Endogenous or exogenous infection?Surg Infect (Larchmt), 2010;11:77-78.

13. Chaudhuri S, Sarkar D, Mukerji R. Diagnosis and management of atypical mycobacterial infection after laparoscopic surgery. Indian J Surg, 2010;72: 43842.
14. Abd-Elhamid N, Kasim K. Port-site non-tuberculous mycobacterial infection after laparoscopic cholecystectomy: A case series study. TAF Prev Med Bull, 2013;12:481-84.

15. Amit KS, GambhirRPS, Nandita HR, Katoch. Nontuberculous mycobacteria in surgical wounds-a rising cause of concern? Indian J Surg, 2010;72:20610 .

16. Atul KS, RakashS, SantoshS.Port site infection in laparoscopic surgeries. Indian Medical Gazette, June 2013;224-29.

17. Holub Z. "Impact of laparoscopic surgery on immune function. 'Clinical and Experimental Obstetrics \& Gynecology, 2002;28.2.

18. Mir MA, Malik UY, Wani H, Bali BS. Prevalence, pattern, sensitivity and resistance to antibiotics of different bacteria isolated from port site infectionin low risk patients after elective laparoscopic cholecystectomy for symptomatic cholelithiasis at tertiary care hospital of Kashmir. Int Wound J, 2013; 10:110-113.

19. Yanni F, Mekhail P, Morris-Stiff G. A selective antibiotic prophylaxis policy for laparoscopic cholecystectomy is effective in minimizing infective complications. Ann R Coll Surg Eng,2013;95:345-348.

20. Taj MN, Iqbal Y, Akbar Z. Frequency and prevention of laparoscopic port site infection. J Ayub Med Coll Abbottabad, 2012;24:197 -199.

21. Shindholimath VV, Seenu V, Parshad R, Chaudhry $\mathrm{R}$, Kumar A. Factors influencing wound infection following laparoscopic cholecystectomy. Trop Gastroenterol, 2003;24:90-92.

22. Den Hoed PT, Boelhowuer RU, Veen HF, Hop WC, BruiningHA.Infections and bacteriological data after laparoscopic and open gall bladder surgery. $J$ Hosp Infect, 1998;39:27-37.

23. Yi F, Jin WS, Xiang DB, Sun GY, Huaguo D. Complications of laparoscopic cholecystectomy and its prevention: a review and experience of 400 cases. Hepatogastroenterology, 2012;59:47-50.

24. Triantafyllidis I, Nikoudis N, Sapidis N, Chrissidou M, Kalaitsidou I, Chrissdis T. Complications of laparoscopic cholecystectomy: our experience in a district general hospital. Surg Laparosc Endosc Percutan Tech, 2009;19:449-458.

25. Chuang SC, Lee KT, Chang WT, Wang SN, Kuo KK, Chen JS, Sheen PC. Risk factors for wound infection after cholecystectomy. J Formos Med Assoc, 2004;103:607-612.

26. Mumtaz KH Al-Naser. Port Site Infections After Laparoscopic Cholecystectomy. International Journal of Medical Research \& Health Sciences, 2017;6(6): 132137. 
27. Scott JD, Forrest A, Feuerstein S, Fitzpatrick P, Schentag JJ. Factors associated with post operative infection. Infect Control Hosp Epidemiol.2001;22:347351.28. NupurGupte, JigneshB.Rathod, Vipul D. Yagnik. A Study of a Prevalence of Port Site Infections in Laparoscopic Surgery in a Tertiary Care Centre in the Rural Set Up. British Journal of Medicine \& Medical Research, 2017;20(10): 1-9.

29. Owens CD, Stoessel K. Surgical site infections: epidemiology, microbiology and prevention. $J$ Hosp Infect, 2008; 70(Suppl) 2: 3-10.

30. Boni L, Benevento A, Rovera F, Dionigi G, Di Giuseppe M, Bertoglio C, Dionigi R. Infective complications in laparoscopic surgery. Surg Infect (Larchmt), 2006; 7(Suppl 2):109-111.

31. Javeria Usman, Abid Janjua, Khalil Ahmed. The Frequency of Port-Site Infection in Laparoscopic Cholecystectomies. J M H S, 2016; 10(4):1324-1326. 32.Mayol Julio, et al." Risks of the minimal access approach for laparoscopic surgery: multivariate analysis of morbidity related to umbilical trocar insertion". World Journal of Surgery, 1997; 21(5): 529533.

33. Mangram AJ, Horan TC, Pearson ML, Silver LC, Jarvis WR. Guideline for the prevention of Surgical Site Infection. Centers for Disease Control and Prevention (CDC) Hospital Infection Control Practices Advisory Committee. Am J Infect Control, 1999;27: 97-132.

34. Kownhar H, Shankar EM, Vignesh R, Sekar R, Velu $\mathrm{V}$, Rao UA. High isolation rate of Staphylococcus aureas from surgical site infection in an Indian hospital. J Antimicrob Chemother, 2008;61: 758-760.
35. Warren L. Mycobacteria, in Review of Medical Microbiology and Immunology. 2014,13 thedn, McGraw Hill Education, LANGE, New York, USA,408-18.

36. Jagadish N, Sameer R,Omprakash R. Port-site tuberculosis: A rare complication following laparoscopic cholecystectomy. Scand J Infect Dis, 2002;34:928-29.

37. Sethi S, Sharma M, Ray P, Singh M, Gupta A. Mycobacterium fortuitum wound infection following laparoscopy. Indian J Med Res, 2001;113:83-84.

38. Wisconsin Department of Health Services, Division of Public Health. Atypical mycobacteria, 2015(08/ 2015);42027.

39. World Health Organization. Global Tuberculosis Control (2010) WHO/HTM/TB/2010.7. Geneva. World Health Organization.

40. P.T. Reid, J.A. Innes. Respiratory disease, in Davidson's Principles \& Practice of Medicine. 2014,22 ${ }^{\text {nd }}$ edn, Elsevier Limited, Churchill Livingstone, 688-96.

41. Sanjay M, Kapil DS, Jyotsna S, Nisha M. Port site tuberculosis presenting as nonhealing sinus after laparoscopic appendicectomy. IndianJ Surg (December 2015); 77(Suppl 2):735-37.

42. Faridi SH, Siddiqui B, Singh KD, Aslam M. Port site tuberculosis after laparoscopic cholecystectomy: A rare complication with review of literature. Int $J$ Health Allied Sci, 2016; 5(2):123-25.

43. Baqui MA. Port site tuberculosis after laparoscopy. JAFMC Bangladesh, 2011;7(2):47-49. 